\title{
Molecular sexing of threatened Gyps vultures: an important strategy for conservation breeding and ecological studies
}

Prabhakar B Ghorpade, Praveen K Gupta ${ }^{2}$, Vibhu Prakash ${ }^{3}$, Richard J Cuthbert ${ }^{4}$, Mandar Kulkarni ${ }^{3}$, Nikita Prakash ${ }^{3}$, Asit Das ${ }^{1}$, Anil K Sharma ${ }^{1}$ and Mohini Saini ${ }^{* *}$

\begin{abstract}
During the last two decades populations of three resident species of Gyps vulture have declined dramatically and are now threatened with extinction in South Asia. Sex identification of vultures is of key importance for the purpose of conservation breeding as it is desirable to have an equal sex ratio in these monogamous species which are housed together in large colony aviaries. Because vultures are monomorphic, with no differences in external morphology or plumage colour between the sexes, other methods are required for sex identification. Molecular methods for sex identification in birds rely on allelic length or nucleotide sequence discrimination of the chromohelicase-DNA binding (CHD) gene located on male and female chromosomes ZZ and ZW, respectively. We characterized the partial sequences of CHD alleles from Gyps indicus, Gyps bengalensis, Gyps himalayensis and Aegypius monachus and analysed the applicability of five molecular methods of sex identification of 46 individual vultures including 26 known-sex G. bengalensis and G. indicus. The results revealed that $W$-specific PCR in combination with ZW-common PCR is a quick, accurate and simple method, and is ideal for sex identification of vultures. The method is also suitable to augment ecological studies for identifying sex of these endangered birds during necropsy examinations especially when gonads are not apparent, possibly due to regression during non-breeding seasons.
\end{abstract}

Keywords: Molecular sex identification, Gyps vulture, Cinereous vulture, Vulture conservation, Captive breeding

\section{Background}

Nine species of vultures in the family Accipitridae are found in India, three of which are endemic to South and South-East Asia (the Oriental white-backed vulture (Gyps bengalensis), long-billed (G. indicus) and slenderbilled vulture (G. tenuirostris) and are classified as Critically Endangered by the International Union for Conservation of Nature and Natural resources and are at high risk of extinction in the wild (IUCN, 2011). In India, populations of $G$. bengalensis have declined by more than $99.9 \%$ while those of G. indicus and G. tenuirostris have declined by around $97 \%$ between the early 1990s and 2007 (Prakash et al. 2007). Similar reductions in vulture

\footnotetext{
* Correspondence: mohini@ivri.res.in

${ }^{1}$ Centre for Wildlife Conservation, Management \& Disease Surveillance, Indian Veterinary Research Institute, Izatnagar 243 122, India

Full list of author information is available at the end of the article
}

populations have been recorded in Pakistan and Nepal (Pain@ et al. 2008). Although the Himalayan griffon (G. himalayensis) is not considered threatened (under category Least Concern) (IUCN, 2011), its population decline has been recorded in Nepal (Acharya et al. 2009). The status of another species, the Cinereous Vulture (Aegypius monachus), is classified as Near Threatened as per IUCN (IUCN, 2011). Veterinary use of non-steroidal anti-inflammatory drugs (NSAIDs) such as diclofenac and ketoprofen have been shown to be toxic to Gyps vultures and are responsible for the decline of these species (Oaks et al. 2004; Green et al. 2006, 2007; Swan et al. 2006; Cuthbert et al. 2009; Naidoo et al. 2009, 2010; Das et al. 2011). In contrast the NSAID meloxicam has been demonstrated to be a safe and effective alternative drug for veterinary use (Swan et al. 2006; Swarup et al. 2007). Although the veterinary use of diclofenac has been banned in India, Pakistan and Nepal (Kumar 2006; Singh 2008), it's illegal use is still 
apparent, as diclofenac residues are still prevalent in cattle carcasses across India at concentrations sufficient to cause declines in vulture populations (Cuthbert et al. 2011a, 2011b; Saini et al. 2012).

Due to the massive scale of the population declines and the continued use of diclofenac, populations of the three Critically Endangered resident Gyps species are being bred in captivity in India, Nepal and Pakistan, with the aim that their progeny will be introduced back in to the wild after ensuring that the environment is safe and diclofenac free (MoEF 2006; Bowden 2009).

Vultures are monomorphic monogamous species and hence without knowing the sex of birds it is difficult to maintain the correct sex ratios in aviaries at conservation breeding centres in order to maximise the chances of successful breeding. As well as the key importance of identifying gender for conservation breeding programmes, knowledge of sex is also important to complement forensic studies (An et al. 2007) and investigations on evolution and ecology (Griffiths and Tiwari 1995; Costantini 2008; Fukui et al. 2008).

Various techniques have been employed for sex determination of monomorphic birds such as laparotomy (Risser 1971), laparoscopy (Richner 1989), flow cytometry (Nakamura et al. 1990), karyotyping (Hatzofe and Getreide 1990) and Raman spectroscopy (Harz et al. 2008) but molecular methods based on DNA analysis are most prevalent (Fridolfsson and Ellegren 1999). Except for the ratites, that have undifferentiated sex chromosomes, all male birds are homogametic with $Z Z$ sex chromosomes and females are heterogametic with $Z W$ sex chromosomes (Ellegren 1996; Griffiths et al. 1996). The most frequently exploited gene for sex identification is the Chromohelicase DNA binding (CHD) gene that is found conserved on both $\mathrm{W}$ and $\mathrm{Z}$ chromosomes (Griffiths 2000). Intronic length variation in $C H D-Z$ and $C H D-W$ allelles amplified by Griffiths universal $C H D$ primer pair P2/P8 has formed the basis of gender identification in most avian species (Griffiths et al. 1998; Fridolfsson and Ellegren 1999). However, in certain species of Accipitridae there is an extremely short difference in intronic length between $C H D-Z$ and $C H D-W$ P2/P8 amplicon which makes sex identification more difficult and inaccurate (Ito et al. 2003; Chang et al. 2008). Hence, in order to circumvent the limitation of conventional PCR (Fridolfsson and Ellegren 1999), different approaches detecting small variation in nucleotides like Amplification Refractory Mutation System (ARMS) (Ito et al. 2003), Restriction Fragment Length Polymorphism (RFLP) (Sacchi et al. 2004), Single strand conformation polymorphism (SSCP) (Ramos et al. 2009), Melting Curve analysis (Chang et al. 2008a), $Z W$ common and $W$-specific PCR (Chang et al. 2008b), TaqMan Probe-based real time PCR (Chang et al. 2008c; Chou et al. 2010) have been suggested in order to identify gender in these species.
Old World vultures along with other birds of prey belong to the taxonomic order Falconiformes, family Accipitridae, and subfamily Accipitrinae (Chang et al. 2008b, 2008c). Due to their position within the Accipitridae it was observed that intronic length variation of $C H D-Z$ and $C H D-W$ amplicon in Griffiths universal $C H D$ primer pair P2/P8 based PCR is unlikely to be suitable for sex discrimination in G. indicus or G. bengalensis (Reddy et al. 2007). However, a similar approach (Kahn et al. 1998) using denaturing polyacrylamide gel electrophoresis combined with autoradiography has been reported to sex nestlings of these two species (Arshad et al. 2009). In the present study, based upon the chromohelicase gene sequences in male $(Z Z)$ and female birds $(Z W)$, the accuracy and reliability of five different approaches are compared for molecular gender identification in three vulture species (G. indicus, G. bengalensis, G. himalayensis) in order to identify an accurate and simple test to support the captive breeding programmes.

\section{Results}

\section{Sequence characterization of CHD-Z and CHD-W} sequences

The $C H D-Z$ and $C H D-W$ sequences from the four vulture species used in this study were amplified and the sequences were determined. These sequences were submitted to GenBank and accession numbers obtained were HQ236387, HQ236386 (G. indicus); HQ236388, HQ236385 (G. bengalensis); HQ236384, HQ236383 (G. himalayensis); HQ236382 (A. monachus). Independent alignment reports for $C H D-Z$ and $C H D-W$ sequences were prepared (Figure $1 \mathrm{~A}$ and $\mathrm{B}$ ), where primer binding regions for P2, P8, NP, MP; $Z W$-Common and $W$-specific primers and probes as well as restriction site for BamHI and RsaI were located. The primer binding region for MP and $W$-specific primers were found in all $C H D-W$ but not in $C H D-Z$ sequences. The recognition sequence for BamHI was found on $C H D-Z$ but was absent on the $C H D-W$ sequence, whereas the $R s a \mathrm{I}$ restriction site was located at different positions in the $C H D-Z$ and $C H D-W$ sequences. Based on these identified sequences the applicability and accuracy of PCR-RFLP, ARMS-PCR, $W$-specific PCR and TaqMan probe based real-time PCR methods for sex identification was tested for all four species of vultures (Table 1).

\section{Standardization of PCR-based molecular methods for sex identification}

\section{i) Conventional PCR-RFLP}

For standardization of conventional PCR-RFLP, known sex samples from G. bengalensis and G. indicus, G. himalayensis and $A$. monachus were used. It was evident from 


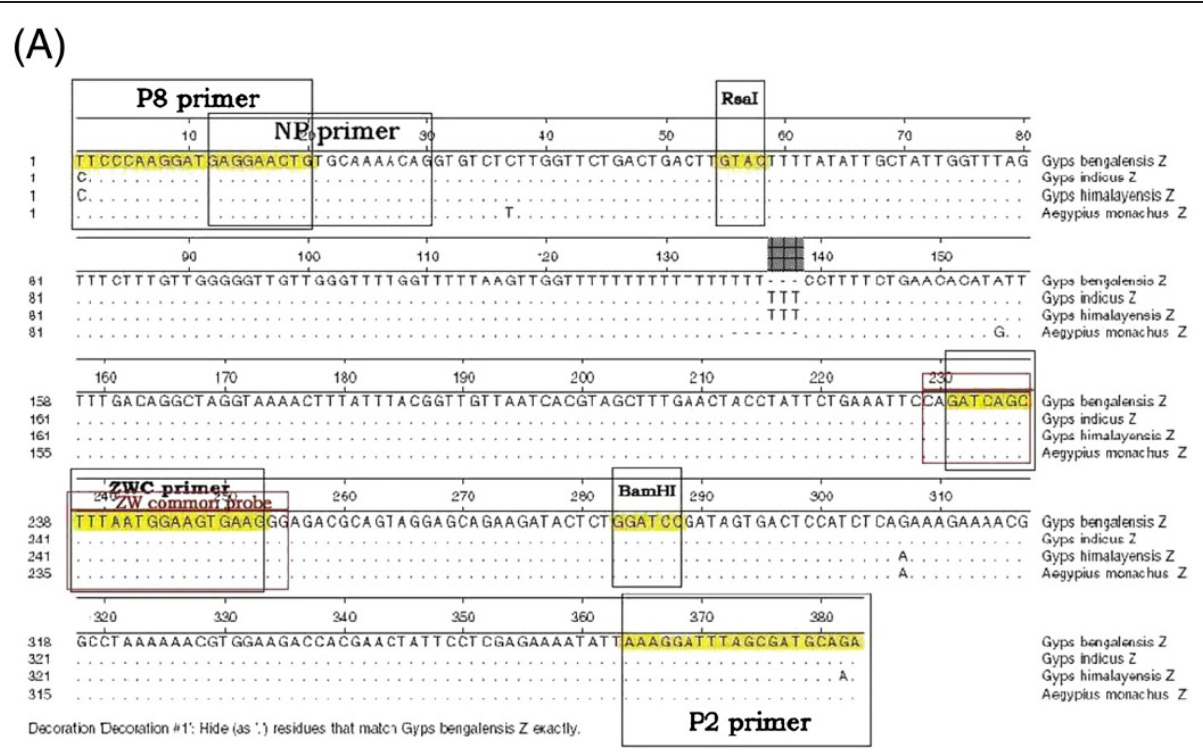

(B)

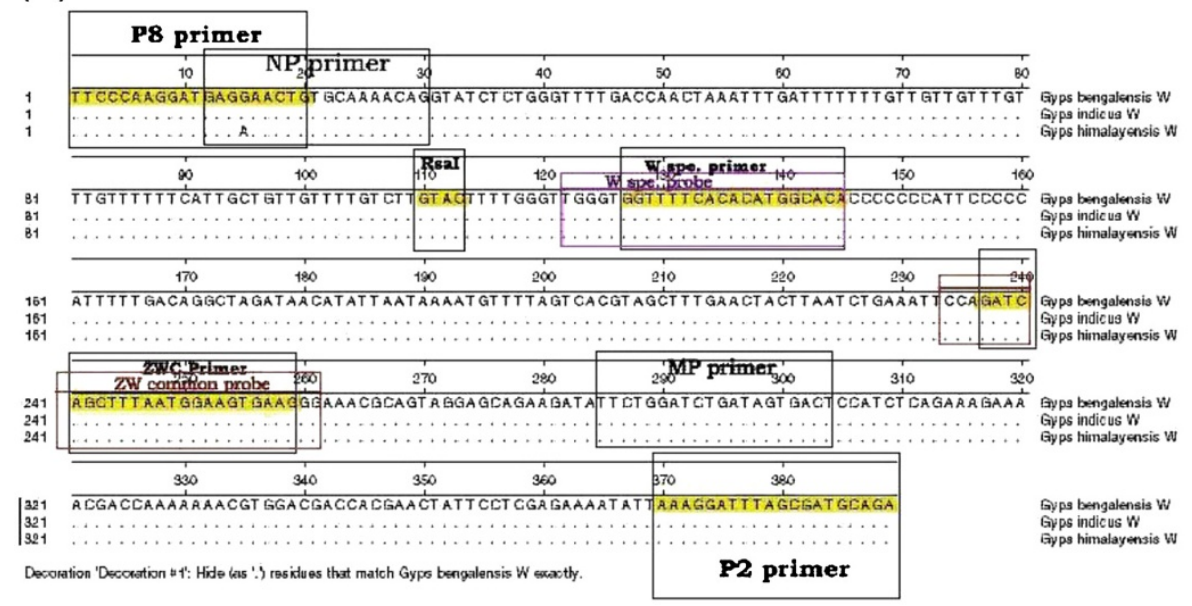

Figure 1 Sequence alignment of CHD-Z and CHD-W allele sequences amplified by Griffith's universal CHD primer pair P2/P8 in four species of vultures (Gyps bengalensis, Gyps indicus, Gyps himalayensis, Aegypius monachus) by ClustalW (MegAlign DNAstar). The sequences of primers P2, P8, NP, MP, ZW common primer and probe, W-specific primer and probe recognition sites; BamHI and Rsal restriction sites are boxed. (--) Dashed lines indicate sequence similarity. A.) Alignment of CHD-Z sequences. B.) Alignment of CHD-W sequences.

sequence analysis (Figure $1 \mathrm{~A}$ and $\mathrm{B}$ ) and the predicted fragment pattern (Table 1) that the test employed for sex identification of G. bengalensis, G. indicus, or G. himalayensis is expected to produce a similar pattern on agarose gel. Figure 2 represents the results for $G$. bengalensis male (P33) and female (P10) birds. Similar patterns of results were found with other species of vultures as predicted (data not shown). PCR amplified products (383 bp in case of $C H D-Z$ and 389 bp in case of $C H D-W$ ) as expected for $G$. bengalensis were obtained using Griffith's universal $C H D$ primer pair which could not be resolved in agarose gel (Figure 2A, L1 and 2B, L1). On restriction digestion with $\mathrm{BamHI}$, female CHD gene yielded three fragments (389 bp, $283 \mathrm{bp}, 100 \mathrm{bp}$ ) (Figure 2B, L2), while male $C H D$ gene yielded two fragments $(283 \mathrm{bp}$, $100 \mathrm{bp}$ ) (Figure 2A, L2). Using RsaI, there were four fragments (327 bp, 278 bp, 111 bp, 56 bp) (Figure 2B, L3) for females, and two fragments (327 bp, $56 \mathrm{bp}$ ) for males (Figure 2A, L3). This indicated that PCR-RFLP using either BamHI or RsaI could be used for sex identification in all the species of vultures.

\section{ii) ARMS-PCR}

In ARMS-PCR using P2, MP and NP primers, the male bird yielded a single amplified product of $372 \mathrm{bp}$ 
Table 1 Predicted gel pattern for analysing various sex identification methods (size in bp)

\begin{tabular}{|c|c|c|c|c|c|c|c|c|c|c|c|}
\hline \multirow[t]{2}{*}{ P2/P8 } & & \multicolumn{4}{|c|}{ PCR-RFLP } & \multirow{2}{*}{\multicolumn{2}{|c|}{$\begin{array}{l}\text { ARMS-PCR (Multiplex with } \\
\text { P2/NP/MP primers) }\end{array}$}} & \multicolumn{4}{|c|}{$W$-specific PCR } \\
\hline & & \multicolumn{2}{|c|}{$\begin{array}{l}\text { BamHI digest of P2/P8 } \\
\text { amplicon }\end{array}$} & \multicolumn{2}{|c|}{$\begin{array}{l}\text { Rsal digest of P2/P8 } \\
\text { amplicon }\end{array}$} & & & \multicolumn{2}{|c|}{$\begin{array}{l}\mathrm{P} 2 / Z W \\
\text { common }\end{array}$} & \multicolumn{2}{|l|}{$\begin{array}{l}\mathrm{P} 2 / W \\
\text {-specific }\end{array}$} \\
\hline \multicolumn{12}{|c|}{ Gyps bengalensis } \\
\hline Female & Male & Female & Male & Female & Male & Female & Male & Female & Male & Female & Male \\
\hline $389(W)$ & Nil & 389 & & 327 & 327 & 378(P2/NP-W) & & $153(W)$ & & $263(W)$ & $\mathrm{Nil}$ \\
\hline \multirow[t]{3}{*}{$383(Z)$} & $383(Z)$ & 283 & 283 & 278 & & 372(P2/NP-Z) & $372(\mathrm{P} 2 / \mathrm{NP}-\mathrm{Z})$ & $153(Z)$ & $153(Z)$ & & \\
\hline & & 100 & 100 & 111 & & 293(MP/NP-W) & Nil & & & & \\
\hline & & & & 56 & 56 & & & & & & \\
\hline \multicolumn{12}{|c|}{ Gyps indicus } \\
\hline $389(\mathrm{~W})$ & Nil & 389 & & 330 & 330 & 378(P2/NP-W) & & $153(W)$ & & $263(W)$ & $\mathrm{Nil}$ \\
\hline \multirow[t]{3}{*}{$386(Z)$} & $386(Z)$ & 286 & 286 & 278 & & 375(P2/NP-Z) & 375(P2/NP-Z) & $153(Z)$ & 153(Z) & & \\
\hline & & 100 & 100 & 111 & & 293(MP/NP-W) & $\mathrm{Nil}$ & & & & \\
\hline & & & & 56 & 56 & & & & & & \\
\hline \multicolumn{12}{|c|}{ Gyps himalayensis } \\
\hline $389(W)$ & Nil 386(Z) & 389 & & 330 & 330 & 378(P2/NP-W) & & $153(W)$ & & $263(W)$ & $\mathrm{Nil}$ \\
\hline \multirow[t]{3}{*}{$386(Z)$} & & 286 & 286 & 278 & & 375(P2/NP-Z) & 375(P2/NP-Z) & $153(Z)$ & $153(Z)$ & & \\
\hline & & 100 & 100 & 111 & & 293(MP/NP-W) & $\mathrm{Nil}$ & & & & \\
\hline & & & & 56 & 56 & & & & & & \\
\hline \multicolumn{12}{|c|}{ Aegypius monachus } \\
\hline \multirow[t]{2}{*}{-} & $380(Z)$ & - & 280 & - & 324 & - & 369(P2/NP-Z) & - & $153(Z)$ & - & $\mathrm{Nil}$ \\
\hline & & & 100 & & 56 & & & & & & \\
\hline
\end{tabular}

(Figure 2A, L4) because there was only one $C H D-Z$ allele while, the female bird yielded three products (378 bp, 372 bp, 293 bp) because female had two alleles namely, $C H D-Z$ and $C H D-W$. Since the products $378 \mathrm{bp}, 372 \mathrm{bp}$ were very close in size, they could not be separated on $3 \%$ agarose gel and appeared as single band (Figure 2B, L4).

\section{iii) $W$-specific PCR}

In the $W$-specific PCR method of sex identification, where Griffith's universal $C H D$ primer P2 was used as the forward primer and $C H D-Z W$ common primer as the reverse primer (which anneals to both the $C H D-Z$ and $C H D-W$ sequence) this generated one product (153 bp) with both male and female birds (Figure 2A, L5 and 2B, L5). When Griffith's universal CHD primer P2 was used as a forward primer and $W$-specific primer was used as reverse primer (which anneals to only the female specific $C H D-W$ allele) this yielded one product (263 bp) with female birds (Figure 2A, L6) and no product with male birds as the $W$-specific primer does not bind with the $C H D-Z$ allele (Figure 2B, L6). iv) TaqMan probe based qualitative real-time PCR (qPCR)

Using TaqMan based qPCR based on an allele discrimination option, where Griffith's universal CHD primer pair P2/P8 was used along with $Z W$ common (HEX-labelled) and $W$ - specific (FAM-labelled) probes, sex identification was undertaken on the basis of a colour plot. In females, where both $C H D-W$ and $C H D-Z$ alleles were present, both $Z W$ common and $W$ - specific probes gave dual colour (HEX- and FAM-specific fluorescence). While in males where only one allele $(C H D-Z)$ was present, only one colour (HEX-specific fluorescence) could be detected. Results from genomic DNA of known sex G. bengalensis and G. indicus female and male birds are shown (Figure 3A-E).

\section{Application of the molecular methods for sex identification}

36 samples (26 tissue samples and 10 blood samples) were analysed using conventional PCR with Griffith's universal $C H D$ primer pair P2/P8, a single PCR product was obtained in all samples with good quality genomic 


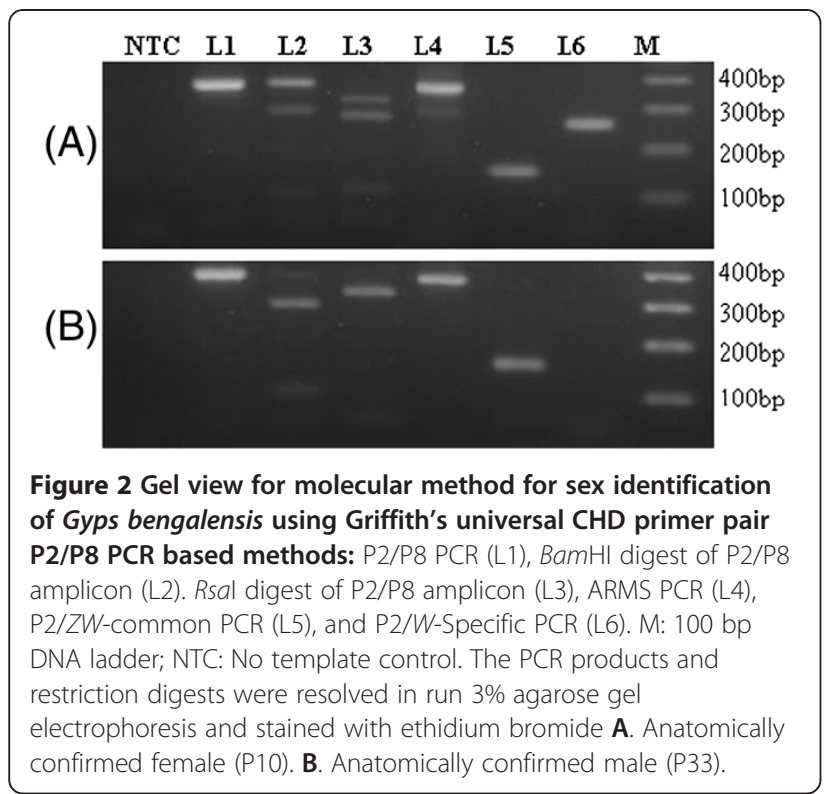

DNA. Further, using BamHI and RsaI restriction digestion in PCR-RFLP, sex in all samples could be successfully identified. Gel photographs of representative samples are shown (Figure 4A-B).

In ARMS-PCR (Figure 4C), where multiplexing of primers was done to analyse the sex of birds as female (with two bands) or male (with one band), sex in all samples could be identified. The female samples showed two bands of approximately $378 \mathrm{bp}$ and $293 \mathrm{bp}$, whereas males yielded a single band of $372 \mathrm{bp}$ in G. bengalensis, $375 \mathrm{bp}$ in G. indicus as well as in G. himalayensis, and $369 \mathrm{bp}$ in A. monachus as predicted in Table 1.

The $W$-specific PCR approach employing P2/ZW Common primer pair or $\mathrm{P} 2 / W$-specific primer pair in independent reactions proved useful in identifying sex of all bird samples. P2/ZW common amplicon of $153 \mathrm{bp}$ authenticated the $C H D$ specific product obtained from all genomic DNA (Figure 4D). One band of $263 \mathrm{bp}$ belonging to $\mathrm{P} 2 / \mathrm{W}$-specific product was visualized only in the female samples (Figure 4E). This method was found useful in analyzing certain samples even with degraded DNA.

Similarly, the TaqMan based qPCR approach was successful in identifying sex based on allellic discrimination. Figure 5 represents the application of the Realtime qPCR to identify Gyps bengalensis and Gyps indicus female birds. The sex of the birds obtained by qPCR matched with that obtained by other agarose gel-based molecular methods.

Sex of 17 dead and nine live birds were identified by molecular methods and the results were verified from the breeding centre. Sex identified by molecular methods from 13 dead birds matched with the known sex. The sex of four samples (P7, P12, P43 and P48) that were found to be female using all of the molecular methods were previously identified as males during field post-mortems. The sexes of all the nine live birds identified by molecular methods matched with the observed sex based upon their biological behaviour in the breeding centre. The sex of a further 12 dead and eight live birds was identified based on results of the molecular methods detailed above and successfully classified sex in three Gyps species (G. indicus, G. bengalensis and G. himalayensis).

\section{Discussion}

To evaluate different molecular methods for sex identification of vultures we determined the $C H D-Z$ and $C H D$ $W$ gene sequences from $G$. bengalensis, $G$. indicus, $G$. himalayensis and $A$. monachus vulture species and seven sequences have been submitted to GenBank (HQ236382HQ236388). Multiple sequence alignment of $C H D-W$ and $C H D-Z$ sequences revealed high sequence similarity which suggested that a common molecular method could be utilised for sex identification in all four of these vulture species (three of one genus, Gyps and one of different genus, Aegyps). Further, due to the sequence similarity of the primer binding region of Griffith's universal $C H D$ primer pair P2/P8 on the $C H D-Z$ and $C H D-W$ gene sequences, the amplicon from $C H D-Z$ and $C H D-W$ genes could be obtained in PCR. However, due to the small difference in intronic length (amplicon sizes of $C H D-Z$ and $C H D-W$ alleles with difference of 6 bp with G. bengalensis and 3 bp with G. indicus and G. himalayensis), it was not possible to differentiate males and females using standard agarose gel electrophoresis. Similar findings have been reported in other species of birds and in particular among raptors (Fridolfsson and Ellegren 1999; Ito et al. 2003; Sacchi et al. 2004; Reddy et al. 2007; Chang et al. 2008b, 2008c; Chou et al. 2010). Of the four species of vultures used in the present study, A. monachus is not being maintained in captivity. Only one tissue sample of this species was available that was collected from post-mortem of a single bird carcass available in the field. Considering the limitation in number of samples for A. mona chus, we have included only the characterisation of $C H D-Z$ sequence obtained from one male bird for use in application of molecular methods. The proposed methodologies are likely to be used for sex differentiation from more field specimens of cinereous vultures in future.

To discriminate $C H D-Z$ and $C H D-W$ amplicons and to identify male and female vultures, we analysed four different molecular approaches which have been reported as useful in differentiating sex of eagles and falcons (Ito et al. 2003; Sacchi et al. 2004; Chang et al. 2008b, 2008c; Chou et al. 2010; Reddy et al. 2007; Nesje and Roed 2000; Busch et al. 2005). 


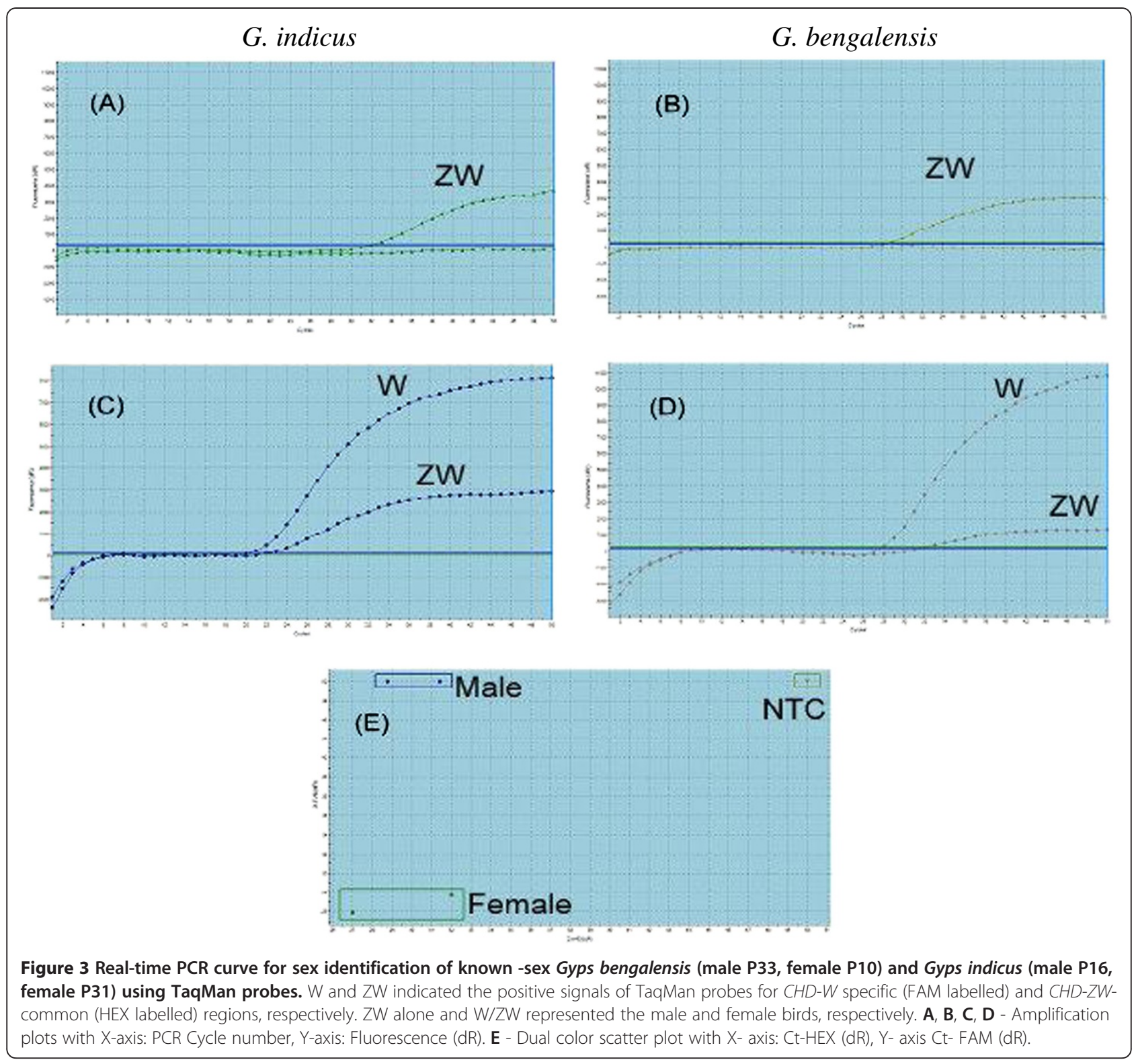

On analysis of nucleotide sequences for $C H D-Z$ and $C H D-W$ amplicons for the RsaI restriction site, two fragments with $C H D-Z$ amplicon and two fragments of different length with $C H D-W$ amplicon were predicted. PCR-RFLP in our study, yielded sex differentiating fragment patterns as digestion of P2/P8 amplicon by RsaI produced four fragments in the case of female birds and two fragments for males. Similarly, PCR-RFLP using BamHI yielded three fragments with females and two with males. Digestion of P2/P8 PCR product using DraI and RsaI restriction enzymes did not yield RFLP pattern expected from analysis of sequences previously published for the species G. indicus (DQ156155 and DQ156156) and G. bengalensis (DQ156153 and DQ156154) by Reddy et al. (2007). The restriction enzymes predicted from sequences (HQ236382-HQ236388) obtained in the present study yielded expected RFLP pattern (Table 1) in all the samples that were analysed. Thus, it was concluded that PCR-RFLP using BamHI or RsaI restriction enzymes can be successful for the sex identification of the four vulture species of interest in our study. The PCR-RFLP method has previously been used for sex identification of the Short-toed Eagle (Circaetus gallicus) using HaeIII for CHD-Z and Asp700I for CHD-W (Sacchi et al. 2004).

Another approach using universal gender identification $C H D-Z W$ common and $W$-specific primers in combination with Griffith's universal CHD primer P2 in two independent reactions has been reported earlier for Crested Serpent Eagles, where standard agarose gels were 


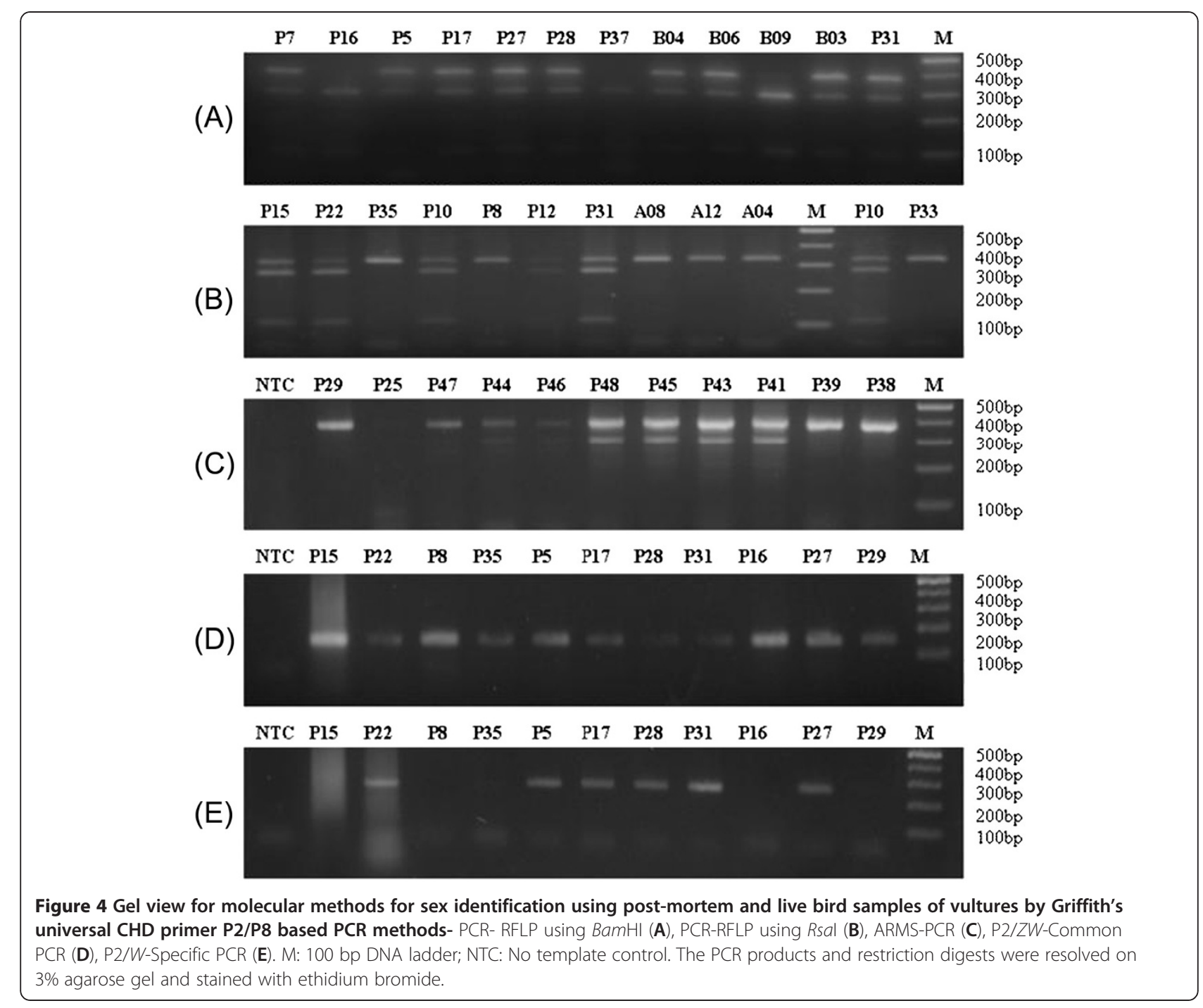

shown to easily distinguish between the 148 bp CHD-ZW and the 258 bp CHD-W PCR products (Chang et al. $2008 \mathrm{~b})$. These reported primers were aligned on vulture sequences obtained in the present study and were found suitable for molecular discrimination of sexes for $G$. indicus $(\mathrm{n}=14)$, G. bengalensis $(\mathrm{n}=28)$ and $\mathrm{G}$. himalayensis $(\mathrm{n}=3)$. This test was found suitable for several reasons- 1) easy interpretation of results in agarose gel as presence or absence of the $C H D W$-specific PCR product; 2) The PCR product size difference of $110 \mathrm{bp}$ in $C H D-Z$ and $C H D \mathrm{~W}$ amplicons with these primers was far easier to differentiate in agarose gel than Griffith's universal CHD primer pair P2/P8 (only 3-6 bp difference); 3 ) it can be employed for high throughput sex identification of vultures using real-time PCR combined with melting curve analysis, and 4) The PCR product obtained is relatively small size (153 from $C H D-Z$ and 263 bp from $C H D-W$ ) and thus, permits the application of this test with degraded DNA samples. In our study, we could not get adequate results with Griffith's universal CHD primer pair P2/P8 due to the large size of the expected product (approximately $390 \mathrm{bp}$ ) in some samples of poor quality genomic DNA, but the $W$-specific approach could prove useful in identifying sex of post-mortem samples. This $W$-specific PCR has also been shown to be an efficient and reliable method to identify sex of American Coots (Fulica americana) where $C H D-Z$ polymorphism does not permit accurate sexing by traditional methods (Shizuka and Lyon 2008).

Further, sex determination using ARMS-PCR based on multiplexing of three primers namely, NP, MP and Griffith's universal CHD primer P2, was evaluated. The primers NP and P2 yielded a single PCR product with male birds. Due to point mutations in $C H D-Z$ and $C H D-$ $W$ sequences, one primer (MP) having 3'- mismatch with CHD-Z allele amplified product (293 bp) only with $C H D-W$ allele and yielded two PCR products with female birds. This ARMS-PCR approach has been successfully 


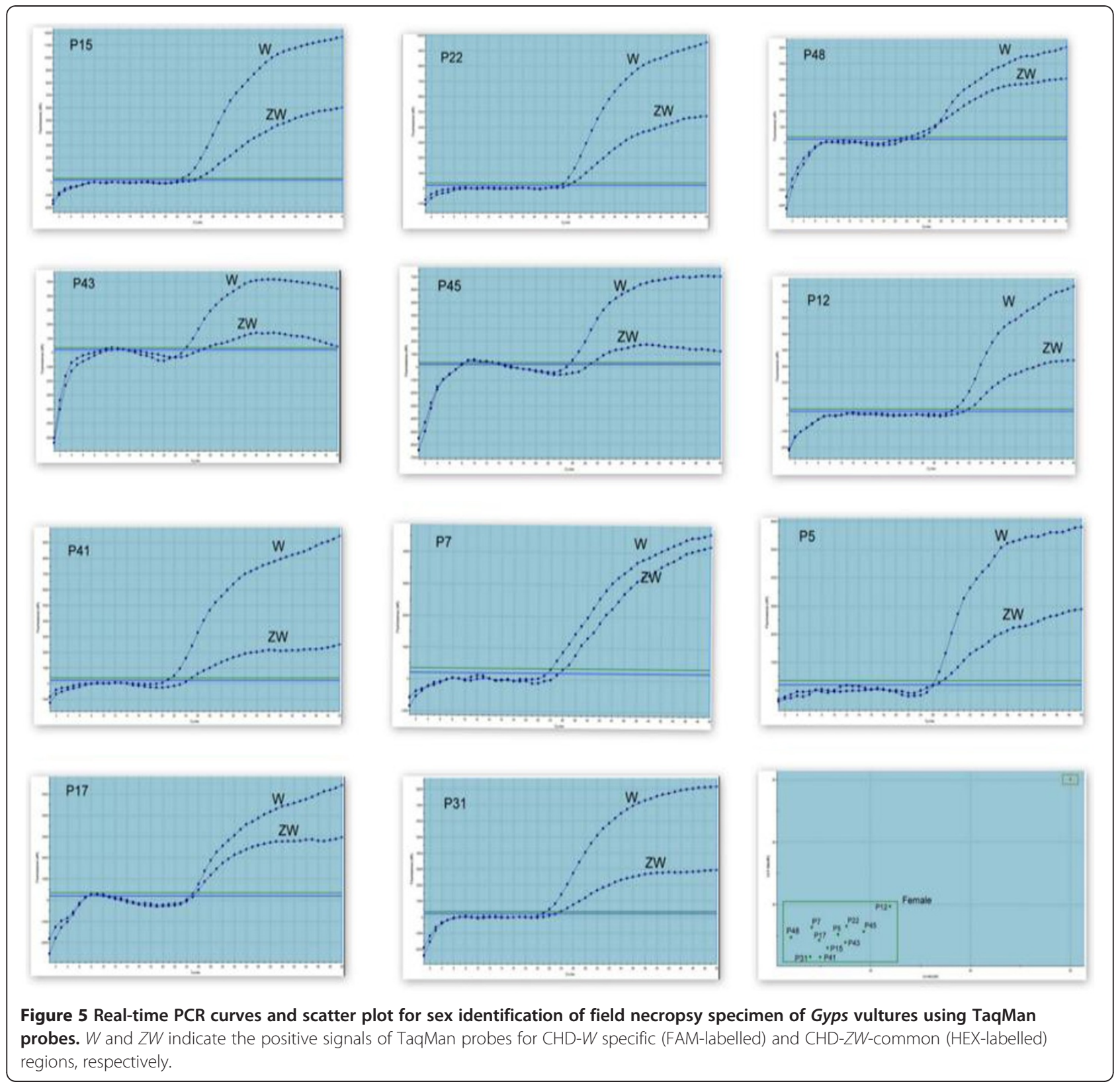

reported for sex identification in a range of Falconiformes species (Ito et al. 2003; Chang et al. 2008a) and use of this approach in G. bengalensis and G. indicus has been indicated earlier but with some reservations (Reddy et al. 2007). However, in our study we have not only strengthened the applicability of this approach on G. indicus and G. bengalensis through validating the results on 26 birds of known sex, but also confirmed that the test can be used for G. himalayensis (female) and A. monachus (male). In our study, the test was found appropriate for male and female sex identification in dead as well as for live bird samples. However, the presence of only one nucleotide mismatch in primer (MP) for
$C H D-Z$ and $C H D-W$ sometimes generated a faint $C H D$ $W$-specific band in males that may lead to some ambiguity with this method.

In real-time PCR using $C H D$ - $W$-specific and $C H D$ $Z W$-common TaqMan probes, fluorescence for both probes was detected with female birds while, fluorescence for $C H D-Z W$-common probe was detected with males. In this study, real-time PCR using these probes was evaluated with tissues from dead birds and blood samples from live birds. This method is quick and robust for unambiguous sex determination in birds and has been utilised for gender identification of a large numbers of raptors (Chang et al. 2008c; Chou et al. 2010). The 
homology of these probes with CHD-Z and CHD-W sequences of $G$. himalayensis and $C H D-Z$ sequence of A. monachus is reported in the present study and further application in a larger number of samples from these two species is warranted to validate this test.

All the molecular methods utilised in our study were employed to identify sex of 29 dead vulture samples. The sex identified by molecular methods for 17 tissue samples from dead vultures was found consistent with that known to the breeding centre for 13 samples. Repeated testing on four mismatched samples, reported in this study, produced the same results under a variety of different molecular sexing methods and we conclude that the original field post-mortems were incorrect in assigning sex. It appears that predicting sex at the time of necropsy may be error prone as gonads are reported to completely regress in birds during the non-breeding season (Hau 2001; Sharah et al. 2007; Nazrul Islam et al. 2012) and this situation may be aggravated when the carcass is putrefied. This might be the reason for the discrepancy in identification of sex from four dead vulture samples. All methods of sex identification for five live G. indicus and G. bengalensis birds and by the CHD-W specific method for an additional four birds were found to match with behavioural records of centre.

In conclusion, the molecular methods utilised in our study can be used to overcome some of the inherent problems of sexing during necropsy and used for accurate identification of sex in ecological studies. Further, these methods are useful for identifying the gender of live birds in the vulture conservation breeding centres and will thereby allow managers to keep balanced sex ratio in breeding aviaries. Among the methods, S. c. hoya $C H D-W$ specific with $C H D-Z W$ internal control primers in combination with Griffith's universal P2 primer provided a relatively simple and robust test for sex identification in the three species of Gyps vultures for individual assays or for high-throughput sex identification and its utility is now being applied and used at the breeding centres in India (CZA, 2011).

\section{Materials and methods}

\section{Sample collection and DNA isolation}

A total of 46 individuals birds were used in the study. Permission to collect tissue samples from dead birds and blood samples from live birds (during routine health checks) at Vulture Conservation Breeding Centre, Pinjore, Haryana was approved by the State Forest Department, Haryana and Ministry of Environment and Forests, Government of India. Tissue samples were available from the necropsies carried out on 29 vulture carcasses. The sex of 17 birds (12 G. bengalensis, four G. indicus and one A. monachus) were identified during post mortem, however in the remaining 12 birds (six G. bengalensis, three G. indicus and three G. himalayensis) sex could not be identified. Blood samples were available from 17 birds from the BNHS Vulture Conservation Breeding Centre (VCBC), Pinjore, Haryana, of which 9 were of known-sex birds (six G. bengalensis and three G. indicus) and eight of unknown-sex (four G. bengalensis and four G. indicus). The sex of live birds in the breeding centres was identified based on their behaviour during copulation and egg laying. Tissue samples from dead birds were collected by trained veterinarians and the sex of all birds was identified during necropsies by visual identification of testes and ovaries.

Genomic DNA was isolated from various tissue types including: pectoral muscle, testes, ovary, crop, and gizzard collected during postmortem using QIAamp DNA mini kit (Qiagen, Valencia, CA, USA) and from blood samples collected over EDTA as an anticoagulant by QIAmp DNA Blood mini kit (Qiagen, Valencia, CA, USA) as per the manufacturers' instructions. The quality of DNA was checked in $0.8 \%$ agarose gel electrophoresis.

\section{Sequence characterization for CHD-Z and CHD-W sequences}

The Griffiths universal CHD primer pair P2/P8 (Griffiths 2000) was used to amplify the partial $C H D$ gene from genomic DNA isolated from known-sex G. bengalensis female (P10) and male (P33); G. indicus female (P17) and male (P35); A. monachus male (P30) and G. himalayensis (P49) (unknown at the time of collection but identified as female in $W$-specific PCR). PCR reaction was performed in $25 \mu \mathrm{l}$ reaction volume consisting of $0.4 \mu \mathrm{M}$ each of P2 (Forward 5'-TCTGCATCGC TAAATCCTTT-3') and P8 (Reverse 5'-CTCCCAAG GATGAGRAAYTG-3') primers, 100-200 ng genomic DNA, $0.2 \mathrm{mM}$ each dNTPs in $1 \mathrm{x}$ reaction buffer containing $2 \mathrm{mM} \mathrm{MgCl}_{2}$ and $1 \mathrm{U}$ Pfu UltraII Fusion $\mathrm{HS}$ DNA polymerase (Stratagene). No template control (NTC) containing no DNA was run with every PCR and precautions were taken to avoid cross-contamination. PCR cycle condition consisted of an initial denaturation at $94^{\circ} \mathrm{C}$ for $4 \mathrm{~min}$, followed by 5 repeated cycles of $94^{\circ} \mathrm{C}$ for $30 \mathrm{sec}, 49^{\circ} \mathrm{C}$ for $30 \mathrm{sec}, 72^{\circ} \mathrm{C}$ for $30 \mathrm{sec} ; 49$ repeated cycles of $94^{\circ} \mathrm{C}$ for $30 \mathrm{sec}, 48^{\circ} \mathrm{C}$ for $20 \mathrm{sec}, 72^{\circ} \mathrm{C}$ for $20 \mathrm{sec}$ and final extension at $72^{\circ} \mathrm{C}$ for $5 \mathrm{~min}$. The PCR products were separated on $3 \%$ agarose gel, purified using QIAquick gel extraction kit (Qiagen, Valencia, CA, USA) and cloned using CloneJET ${ }^{\mathrm{TM}}$ PCR Cloning Kit (Fermentas) following the manufacturer's instructions. The recombinant plasmids were characterized and nucleotide sequences were determined using a T7 promoter primer. The nucleotide sequences for $C H D-Z$ and $C H D-W$ alleles from all species were aligned using MegAlign Lasergene software (DNAstar Inc, USA). 
Restriction endonuclease RsaI and BamHI sites were selected for sex identification in PCR-RFLP analysis.

\section{Standardization of PCR-based molecular methods for sex identification}

\section{i) Conventional PCR-RFLP}

Using Griffiths universal CHD primer pair P2/P8, the amplified PCR products were analysed using restriction endonuclease digestion with RsaI and BamHI and sex was identified. The restriction digestion was performed in a $30 \mu \mathrm{l}$ reaction volume containing $5 \mu \mathrm{l}$ of amplified PCR product and $2 \mathrm{U}$ of restriction enzymes (Rsa $\mathrm{I}$ or Bam HI) and was incubated at $37^{\circ} \mathrm{C}$ overnight. The digested products were separated on $3 \%$ agarose gel along with 100 bp DNA ladder and analysed.

\section{ii) ARMS-PCR}

ARMS-PCR based on 3'-terminal mismatch primer (MP primer) point mutation conserved among Falconiformes $C H D-W$ and $C H D-Z$ sequences previously reported (Ito et al. 2003) was performed to identify sex in vultures with some modifications. Briefly, PCR was done in a $25 \mu \mathrm{l}$ reaction volume containing $0.4 \mu \mathrm{M}$ each of Griffiths universal $C H D$ primer $\mathrm{P} 2$ forward primer, another forward primer MP (5'-AGTCACTATCAGATCCGGAA-3') and reverse primer NP (5'-GAGAAACTGTGCAAAACAG -3'), $100 \mathrm{ng}$ genomic DNA, $0.2 \mathrm{mM}$ each dNTP and 1U of Taq DNA Polymerase (Bangalore Genei, India). PCR amplification cycle involved initial denaturation at $94^{\circ} \mathrm{C}$ for $90 \mathrm{sec}$ followed by 35 cycles of $94^{\circ} \mathrm{C}$ for $30 \mathrm{sec}, 50^{\circ} \mathrm{C}$ for $45 \mathrm{sec}$, $72^{\circ} \mathrm{C}$ for $30 \mathrm{sec}$ and final extention at $72^{\circ} \mathrm{C}$ for $5 \mathrm{~min}$. The amplified PCR products were separated on 3\% agarose gel along with 100 bp DNA ladder and analysed.

iii) $W$-specific PCR

An alternative $W$-specific sex identification method suggested for Crested Serpent Eagle (Spilornis cheela hoya) (Chang et al. 2008b) was also used in this study, where Griffith's universal CHD primer P2 was used as a forward primer and $C H D-W$ primer as a reverse primer which anneals to only the $C H D-W$ allele sequence, or $Z W$-common primer which anneals to both $C H D-Z$ and $C H D-W$ allele sequences. The PCR reaction was performed in a $25 \mu \mathrm{l}$ volume consisting of $0.4 \mu \mathrm{M}$ each of Griffith's universal CHD primer P2 and reverse primer $C H D$ - $Z W$-common (5'-GATCAGCTTTAATGGA AGTGAAG-3') or CHD-W specific (5'-GGTTTTCACAC ATGGCACA-3'), 100 ng genomic DNA, $0.2 \mathrm{mM}$ each dNTP, $1.5 \mu \mathrm{l}$ DMSO and 1U Taq DNA Polymerase (Bangalore Genei, India). The PCR cycling condition employed was an initial denaturation at $94^{\circ} \mathrm{C}$ for $3 \mathrm{~min}$, followed by 45 repeated cycles of $94^{\circ} \mathrm{C}$ for $30 \mathrm{sec}, 56^{\circ} \mathrm{C}$ for $30 \mathrm{sec}, 72^{\circ} \mathrm{C}$ for $20 \mathrm{sec}$, and final extension at $72^{\circ} \mathrm{C}$ for $5 \mathrm{~min}$. The amplified PCR products were resolved on 3\% agarose gel along with $100 \mathrm{bp}$ DNA ladder and analysed for presence (indicating female) or absence (indicating male) of $263 \mathrm{bp} W$-specific product.

\section{iv) TaqMan probe based real-time PCR}

The TaqMan based qualitative real-time PCR (qPCR) based on allele discrimination option for sex identification reported earlier for S. cheela hoya (Chang et al. 2008c) was used. This test utilises the considerable difference in composition of the CHD-W and CHD-Z sequences in vultures, with the $W$-specific probe (5'-FAM-TGTGCCATGTGTGAAAACCACCCA-TAMR A) recognising only the $C H D-W$ region whereas the $Z W$ common probe (5'-HEX-CCCTTCACTTCCAT TAAAGCTGATCTGG-TAMRA) recognises both the Z and $\mathrm{W} C H D$ chromosome regions. The PCR reaction mixture in a $20 \mu \mathrm{l}$ volume consisted of $0.4 \mu \mathrm{M}$ each of Griffith's universal CHD primer pair P2/P8, 50-100 ng genomic DNA, $0.2 \mathrm{mM}$ of each dNTP, 20nM each of $W$-specific and $Z W$ common probes and $1 \mathrm{U}$ of Taq DNA polymerase (Bangalore Genei, India). The DNA template was excluded from no template control (NTC), whereas the probe was excluded from no probe control (NPC). In addition, positive controls (with known male and female DNA samples) were also included in each test. Two steps PCR condition was employed with initial denaturation at $94^{\circ} \mathrm{C}$ for $4 \mathrm{~min}$, followed by 50 repeated cycles of $92^{\circ} \mathrm{C}$ for $15 \mathrm{sec}, 60^{\circ} \mathrm{C}$ for $1 \mathrm{~min}$ in Mx3005P real-time PCR machine (Agilent, USA). The results were recorded as an amplification plot, with text report and alleles discrimination made using $\mathrm{MxPro}^{\mathrm{TM}}$ QPCR software (Agilent, USA) and compared with female and male positive controls.

\section{Application of the molecular methods for sex identification}

All molecular methods were employed for sex identification of vultures using tissue samples obtained during necropsy $(n=17)$ and blood samples obtained from live birds $(n=9)$ for which the sex was known. These tests were then employed for analysing eight blood samples and 12 necropsy tissues from unknown-sex vultures.

\section{Abbreviations}

CHD: Chromohelicase-DNA binding gene; IUCN: International Union for Conservation of Nature; NSAIDs: Non-steroidal antiinflammatory drugs; RFLP: Restriction Fragment Length Polymorphism; ARMS: Amplification Refractory Mutation System; SSCP: Single strand conformation polymorphism; qPCR: Qualitative real-time PCR; VCBC: Vulture Conservation Breeding Centre. 


\section{Competing interests}

The authors declare that they have no competing interests.

\section{Authors' contributions}

PBG carried out cloning and characterization of sequences, performing tests, preparation of the draft and revision of the manuscript. PKG participated in conceiving the design of the study, performed sequence analysis and interpretations and helped in drafting and revising the manuscript. VP conceived the problem, coordinated the collection of samples from field post-mortems and breeding centres and helped to draft the manuscript. RJC participated in coordination of the study, preparing draft and critically revising the manuscript. MK and NP collected the tissue and blood samples from vultures. AD and AKS participated in collection of one tissue sample from Gyps himalayensis from necropsy examination, design of the study and helped to draft the manuscript. MS contributed in conception of the study, execution of the experiments, analysis and interpretation of data, drafting and revising the manuscript. All authors read and approved the final manuscript.

\section{Acknowledgements}

We thank the Director and Joint Director (Research), IVRI, Izatnagar and the Director, BNHS, Mumbai for providing the necessary facilities and funding to carry out this work. We acknowledge laboratory assistance provided by Mr Mohan Bhat, IVRI. The vulture conservation breeding centres in India are run by the Bombay Natural History Society (BNHS), India in collaboration with the state forest departments and Ministry of Environment and Forests, Government of India and supported by UK based organizations Royal Society for Protection of Birds (RSPB), Darwin Initiative for the survival of species, Zoological Society of London and National Birds of Prey Trust.

\section{Author details Bedfordshire, UK. \\ Received: 18 August 2012 Accepted: 7 December 2012 \\ Published: 12 December 2012}

${ }^{1}$ Centre for Wildlife Conservation, Management \& Disease Surveillance, Indian Veterinary Research Institute, Izatnagar 243 122, India. ${ }^{2}$ Division of Veterinary Biotechnology, Indian Veterinary Research Institute, Izatnagar 243 122, India. ${ }^{3}$ Bombay Natural History Society, Hornbill House, S.B. Singh Road, Mumbai 400 001, India. ${ }^{4}$ Royal Society for the Protection of Birds, The Lodge, Sandy,

\section{References}

Acharya R, Cuthbert R, Baral HS, Shah KB (2009) Rapid population declines of Himalayan Griffon Gyps himalayensis in Upper Mustang, Nepal. Bird Conservation International 19:99-107

An J, Lee MY, Min MS, Lee MH, Lee H (2007) A molecular genetic approach for species identification of mammals and sex determination of birds in a forensic case of poaching from South Korea. Forensic Sci Int 167:59-61

Arshad M, Chaudhary MJl, Wink M (2009) High mortality and sex ratio imbalance in a critically declining Oriental White-backed vulture population (Gyps bengalensis) in Pakistan. J Ornithol 150:495-503

Bowden C (2009) The Asian Gyps vulture crisis: the role of captive breeding in India to prevent total extinction. BirdingASIA 12:121-123

Busch JD, Katznerm TE, Bragin E, Keim P (2005) Tetranucleotide microsatellite for Aquila and Haliaeetus eagles. Mol Ecol Notes 5:39-41

Chang HW, Cheng CA, Gu DL, Chang CC, Su SH, Wen CH, Chou CY, Chou TC, Yao CT, Tsai CL, Cheng CC (2008a) High-throughput avian molecular sexing by SYBR green based real-time PCR combined with melting curve analysis. BMC Biotechnol 8:8-12

Chang HW, Chou TC, Gu DL, Cheng CA, Chang CC, Yao CT, Chuang LY, Wen CH, Chou YC, Tan KY, Cheng CC (2008b) An improved PCR method for gender identification of eagles. Mol Cell Probes 22:184-188

Chang HW, Gu DL, Su SH, Chang CC, Cheng CA, Huang HW, Yao CT, Chou TC, Chuang LY, Cheng CC (2008C) High-throughput gender identification of Accipitridae eagles with real-time PCR using TaqMan probes. Theriogenology 70:83-90

Chou TC, Yao CT, Su SH, Hung YC, Chen WS, Cheng CC, Tseng CN, Wang HM, Chou YC, Li SS, Gu DL, Chang HW (2010) Validation of Spilornis cheela hoya TaqMan probes for potential gender identification of many Accipitridae species. Theriogenology 73:404-11
Costantini V, Guaricci AC, Laricchiuta P, Rausa F, Lacalandra GM (2008) DNA sexing in Humboldt Penguins (Spheniscus humboldti) from feather samples. Anim Reproduction Sci 106:162-167

Cuthbert R, Prakash V, Bowden C, Das D, Green RE, Jhala Y, Pain DJ, Senacha KR, Shah N, Taggart MA (2009) Role of veterinary diclofenac in decline of vulture populations in South Asia. Ind Vet Med Journal 29:80-85

Cuthbert R, Taggart MA, Prakash V, Saini M, Swarup D, Upreti S, Mateo R, Chakraborty SS, Deori P, Green RE (2011a) Effectiveness of action in India to reduce exposure of Gyps vultures to the toxic veterinary drug diclofenac. PLoS One 6:e19069

Cuthbert RJ, Prakash V, Saini M, Upreti S, Swarup D, Das A, Green RE, Taggart M (2011b) Are conservation actions reducing the threat to India's vulture populations? Curr Sci 101:1480-1484

Das D, Cuthbert RJ, Jakati RD, Prakash V (2011) Diclofenac is toxic to the Himalayan vulture Gyps himalayensis. Bird Conservation International 21:72-75

Ellegren $H$ (1996) First gene on the avian W chromosome (CHD) provides a tag for universal sexing of non-ratite birds. Proc Roy Soc Biol Sci 263(1377):1635-1641

Fridolfsson A, Ellegren $H$ (1999) A simple and universal method for molecular sexing of non-ratite birds. J Avian Biol 30:116-121

Fukui E, Sugita S, Yoshizawa M (2008) Molecular sexing of Jungle crow (Corvus macrorhynchos japonensis) and Carrion crow (Corvus corone corone) using a feather. Anim Sci J 79:158-162

Green RE, Taggart MA, Senacha KR, Raghavan B, Pain DJ, Cuthbert R (2007) Rate of decline of the oriental white-backed vulture population in India estimated from a survey of diclofenac residues in carcasses of ungulates. PLoS One 2(8):e686

Green RE, Taggart MA, Das D, Pain DJ, Kumar S, Cunningham AA, Cuthbert R (2006) Collapse of Asian vulture populations: risk of mortality from residues of the veterinary drug diclofenac in carcasses of treated cattle. J Appl Ecol 43:949-956

Griffiths R (2000) Sex identification in birds. Semin Avian Exotic Pet Med 9:14-26

Griffiths R, Daan S, Dijkstra C (1996) Sex identification in birds using two CHD genes. Proc Royal Soc - Biol Sci 263:1251-1256

Griffiths R, Double MC, Orr K, Dawson RJG (1998) A DNA test to sex most birds. Mol Ecol 7:1071-1075

Griffiths R, Tiwari B (1995) Sex of the last wild Spix's macaw. Nature 375(6531):375-454

Harz M, Krause M, Bartels T, Cramer K, Rosch P, Popp J (2008) Minimal invasive gender determination of birds by means of UV-resonance Raman spectroscopy. Anal Chem 80:1080-1086

Hatzofe O, Getreide S (1990) Sex determination in vultures and other monomorphic raptors. Torgos 8:27-29

Hau M (2001) Timing of breeding in variable environments: tropical birds as model systems. Horm Behav 40:281-290

IUCN (International Union for Conservation of Nature) (2011) Red list of threatened species, Version Version 2011.2. http://www.iucnredlist.org (Downloaded on 25 April 2012)

Ito H, Sudo-yamaji A, Abe M, Murase T, Tsubota T (2003) Sex identification by alternative polymerase chain reaction methods in falconiformes. Zoological Sci 20:339-344

Kahn NW, John J, Quinn TW (1998) Chromosome-specific intron size differences in the avian CHD gene provide an efficient method of sex identification in birds. Auk 115:1074-1078

Kumar A (2006) Subject: diclofenac for veterinary use. Letter to 'All State Drug Controllers' from the 'Drug Controller General (India)', 11th May 2006, F.No. 18-03/2006/DC

MOEF (Ministry of Environment and Forests) (2006) Action plan for vulture conservation in India. 28, New Delhi, p 1

Naidoo V, Wolter K, Cromarty D, Diekmann M, Duncan N, Meharg AA, Taggart MA, Venter L, Cuthbert R (2010) Toxicity of NSAIDs to Gyps vultures: a new threat from ketoprofen. Biol Lett 6:339-341

Naidoo V, Wolter K, Cuthbert R, Duncan N (2009) Veterinary diclofenac threatens Africa's endangered vulture species. Reg Toxicol Pharmacol 53:205-208

Nakamura D, Tiersch TR, Douglas M, Chandler RW (1990) Rapid identification of sex in birds by flow cytometry. Cytogenet Cell Genet 53:201-205

Nazrul Islam M, Tsukahara N, Sugitaa S (2012) Apoptosis-mediated seasonal testicular regression in the Japanese Jungle crow (Corvus macrorhynchos). Theriogenology 77:1854-1865 
Nesje M, Roed KH (2000) Sex identification in falcons using microsatellite DNA markers. Hereditas 132:261-263

Oaks JL, Gilbert M, Virani MZ, Watson RT, Meteyer CU, Rideout BA, Shivaprasad HL, Ahmed S, Chaudhry MJ, Arshad M, Mahmood S, Ali A, Khan AA (2004) Diclofenac residues as the cause of vulture population decline in Pakistan. Nature 27(6975):630-633

Pain DJ, Bowden CGR, Cunningham AA, Cuthbert R, Das D, Gilbert M, Jakati RD, Jhala Y, Khan AA, Naidoo V, Oaks JL, Parry-Jones J, Prakash V, Rahmani A, Ranade SP, Baral HS, Sanacha KR, Saravanan S, Shah N, Swan G, Swarup D, Taggart MA, Watson RT, Virani MZ, Wolter K, Green R (2008) The race to prevent the extinction of South Asian vultures. Bird Conservation International 18:S30-S48

Prakash V, Green RE, Pain DJ, Ranade SP, Saravanan S, Prakash N, Venkitachalam R, Cuthbert R, Rahmani AR, Cunningham AA (2007) Recent changes in populations of resident Gyps vultures in India. J Bombay Nat His Soc 104(2):129-135

Ramos PS, Bastos E, Mannan RW, Guedes-Pinto H (2009) Polymerase chain reaction-single strand conformation polymorphism applied to sex identification of Accipiter cooperii. Mol Cell Probes 23:115-118

Reddy A, Prakash V, Shivaji S (2007) A rapid, non-invasive, PCR-based method for identification of sex of the endangered Old World vultures (white-backed and long-billed vultures) - implications for captive breeding programmes. Curr Sci 92:659-662

Richner H (1989) Avian laparoscopy as a field technique for sexing birds and an assessment of its effects on wild birds. J Field Ornithol 60(2):137-142

Risser AC (1971) A technique for performing laparotomy on small birds. Condor 73:376-79

Sacchi P, Soglia D, Sandra Maione S, Meneguza G, Campora M, Rasero R (2004) A non-invasive test for sex identification in short-toed eagle (Circaetus gallicus). Mol Cell Probes 18:193-196

Saini M, Taggart MA, Knopp D, Upreti S, Swarup D, Das A, Gupta PK, Niessner R, Prakash V, Mateo R, Cuthbert RJ (2012) Detecting diclofenac in livestock carcasses in India with an ELISA:A tool to prevent widespread vulture poisoning. Environ Pollution 160:11e16

Sharah HA, Buahin GKA, Yusufu SD (2007) Effect of photoperiod changes on breeding activities and weight of sex organs in cattle egrets (Bubulcus ibis L). The Zoologist 5:16-23

Shizuka D, Lyon BE (2008) Improving the reliability of molecular sexing of birds using a W-specific marker. Mol Ecol Resources 8:1249-1253

Singh S (2008) Subject: Prohibition to manufacture, sale and distribution of diclofenac and its formulations for animal use. Letter to 'Manufacturer's Associations' from the 'Drug Controller General (India)', 6th August 2008, F. No. 18-01/2007-DC

Swan G, Naidoo V, Cuthbert R, Green RE, Pain DJ, Swarup D, Prakash V, Taggart MA, Bekker L, Das D, Diekmann J, Diekmann M, Killian E, Meharg AA, Patra RC, Saini M, Wolter K (2006a) Removing the threat of diclofenac to critically endangered Asian vultures. PLoS Biol 4:395-402

Swan GE, Cuthbert R, Quevedo M, Green RE, Pain DJ, Bartels P, Cunningham AA, Duncan N, Meharg AA, Oaks JL, Parry-Jones J, Shultz S, Taggart MA, Verdoorn G, Wolter K (2006b) Toxicity of diclofenac to Gyps vultures. Biol Lett 2:279-282

Swarup D, Patra RC, Prakash V, Cuthbert R, Das D, Avari P, Pain DJ, Green RE, Sharma AK, Saini M, Das D, Taggart MA (2007) Safety of meloxicam to critically endangered Gyps vultures and other scavenging birds in India. Anim Conserv 10:192-198

CZA (Central Zoo Authority) (2011) Working Manual on Conservation Breeding of Vultures. Available at http://www. cza.nic.in

doi:10.1186/2193-1801-1-62

Cite this article as: Ghorpade et al: Molecular sexing of threatened Gyps vultures: an important strategy for conservation breeding and ecological studies. SpringerPlus 2012 1:62.

\section{Submit your manuscript to a SpringerOpen ${ }^{\circ}$ journal and benefit from:}

- Convenient online submission

- Rigorous peer review

- Immediate publication on acceptance

- Open access: articles freely available online

- High visibility within the field

- Retaining the copyright to your article

Submit your next manuscript at $\gg$ springeropen.com 